\title{
Epidemiological profile of nonmelanoma skin cancer in renal transplant recipients: experience of a referral center
}

\author{
Flávia Regina Ferreira ${ }^{1}$ \\ Luiz Fernando Costa Nascimento ${ }^{1}$
}

\author{
Marilia Marufuji Ogawa² \\ Jane Tomimori ${ }^{2}$
}

DOI: $h$ ttp://dx.doi.org/10.1590/abd1806-4841.20142590

\begin{abstract}
BACKGROUND: Nonmelanoma skin cancer is the most common form of cancer in humans and also the malignant disease that is increasingly common among kidney transplant recipients.

OBJECTIVE: To determine the epidemiological characteristics of renal transplant recipients with nonmelanoma skin cancer seen at a referral transplantation center.

METHODS: Cross-sectional descriptive study with renal transplant recipients presenting nonmelanoma skin cancer, treated at a transplantation referral center between 08/01/2004 and 08/31/2009. Analyzed variables were: gender, age, skin phototype, occupational and recreational sun exposure, use of photoprotection, personal and family history of non-melanoma skin cancer, clinical type and location, time between transplantation and the appearance of the first nonmelanoma skin cancer, occurrence of viral warts, timing of transplantation, type of donor, cause of kidney failure, previous transplants, comorbidities, pre-transplant dialysis, type and duration of dialysis. RESULTS: 64 subjects were included. Males - 71.9\%; low skin phototypes (up to Fitzpatrick III) - 89\%; mean age 57.0 years - and mean age at transplant - 47.3 years; sun exposure - $67.2 \%$ occupational - and $64.1 \%$ recreational; photoprotection - 78.2\% (although only $34.4 \%$ in a regular manner); squamous cell carcinoma - $67.2 \%$; squamous cell carcinoma/basal cell carcinoma ratio - 2:1; personal history of nonmelanoma skin cancer - 25\% - and family history $-10.9 \%$; location at photoexposed area - $98.4 \%$; average latency time between transplantation and first nonmelanoma skin cancer appearance - 78.3 months; viral warts (HPV) after transplant - 53.1\%; average timing of transplantation - 115.5 months; living donor - 64.1\%; triple regimen (antirejection) - 73.2\%; comorbidities - 92.2\%; pre-transplant dialysis - $98.4 \%$; hemodialysis - $71.7 \%$; average duration of dialysis - 39.1 months; previous transplants $-3.1 \%$; hypertension as cause of renal failure $-46.9 \%$.

CONCLUSION: This study allowed the epidemiological characterization of a population of kidney transplant recipients with nonmelanoma skin cancer.
\end{abstract}

Keywords: Basal cell carcinoma; Squamous cell carcinoma; epidemiology; Basal cell neoplasms; Squamous cell neoplasms; Skin cancer; transplants

\section{INTRODUCTION}

Non-melanoma skin cancer (NMSC) is the most common form of cancer among humans. At the end of the last century, the study of this malignancy became a constant concern among researchers due to an exacerbated increase in its incidence worldwide, with the detection of high-risk groups remaining a priority for any preventive action. ${ }^{1}$

In recent decades, there has also been a dramatic increase in the number of patients iatrogenically submitted to chronic immunosuppression. This is largely due to antirejection regimens associated with organ transplants. ${ }^{2}$
NMSC is the malignant disease that is most rapidly growing among the group of renal transplant recipients (RTRs). ${ }^{3,4}$ Several factors work together to increase the risk of cutaneous cancer in these patients, such as: sunlight exposure, individual genetic background, family history, race/skin phototype, age, use of immunosuppressive drugs and viral infection.

São Paulo Hospital (HSP) along with the Kidney and Hypertension Hospital (HRH) linked to Federal University of São Paulo - Paulista Medical School (UNIFESP-EPM) constitute the largest healthcare unit in kidney transplant volume in Latin America. Since January 2004, the department of der-

Received on 06.03.2013.

Approved by the Advisory Board and accepted for publication on 05.05.2013.

* This work has been conducted at Solid Organ Transplant Division of the Department of Dermatology at Universidade Federal de São Paulo (Unifesp) - São Paulo $(\mathrm{SP})$, Brazil.

Conflict of interest: None

Financial funding: None

Universidade de Taubaté (Unitau) - Taubaté (SP), Brazil.

Universidade Federal de São Paulo (Unifesp) - São Paulo (SP), Brazil.

(C2014 by Anais Brasileiros de Dermatologia 
matology at UNIFESP-EPM offers a specific clinic for the follow-up of solid organ transplant recipients with dermatoses, the vast majority being RTRs.

Due to our population's diversity, we must establish in our region the epidemiological profile of RTRs with NMSC. Thus, we organized the clinical data recorded during the consultations of RTRs with NMSC and performed a transversal study, collecting information regarding these patients' habits.

\section{MATERIALS AND METHODS}

This is a cross-sectional descriptive study, conducted at the solid organ transplant division of the department of dermatology at Unifesp-EPM, during the period between August $1^{\text {st }} 2004$ and August 31 2009.

To be included in this study the patient had to fulfill the following criteria: age over 18 years, resident of São Paulo State, RTR, no other organ transplant; presence of nonmelanoma skin cancer after the transplant, confirmed by anatomopathological exam; current use of transplant immunosuppressive drugs; having attended the department of dermatology at Unifesp-EPM between August 2004 and August 2009. Individuals that failed to fulfill all of the aforementioned criteria were excluded from the study.

Patients answered a questionnaire applied by the authors and had their skin and mucosae examined by a dermatologist.

The following parameters were studied:

Demographic characteristics: gender (male or female), age (in years), skin phototype (according to Fitzpatrick classification), origin (São Paulo State capital or countryside);

Personal habits: occupational sun exposure (yes or no), duration of occupational sun exposure (in years), length (all day, parts of the day) and number of hours of occupational sun exposure (per day), recreational sun exposure (yes or no), duration of recreational sun exposure (in years), length (all day, parts of the day) and number of hours of recreational sun exposure (per day), type of recreational sun exposure (daily or sporadic), use of photoprotection (yes, regularly; yes, irregularly; no) and length of photoprotection usage (in months);

NMSC related issues: clinical type, first NMSC or not, number of tumors (one or multiple) at the time of the interview, topographical localization of tumors (photoexposed area or not), personal history of NMSC (yes or no), family history of NMSC (yes or no), latency between transplant and tumor appearance (in months), presence of viral warts after transplant (yes or no) and
Transplant related issues: duration of transplant (in months), type of donor (living or deceased), cause of chronic kidney failure, previous kidney transplants (yes or no), comorbidities (yes or no), pre-transplantation dialysis, type of pre-transplantation dialysis (hemodialysis, peritoneal dialysis, both), duration of dialysis (in months).

The occurrence of a new tumor in a patient already included in the study was not considered as a new case.

Tables with mean values, standard deviation, medians, minimum and maximum values and interquartile intervals for continuous variables were constructed. Tables with absolute values and percentages for the categorical variables were also designed.

Computer software SPSS 17.0 was used.

The present study was approved by the Unifesp-EPM Institutional Review Board under number 0948/10.

\section{RESULTS}

Five hundred and twenty four RTR individuals were seen at solid organ transplant division of the department of dermatology at Unifesp-EPM between August $1^{\text {st }} 2004$ and August 31 $1^{\text {st }} 2009$, having being referred from HSP and HRH by their general practitioners or nephrologists on account of dermatological lesions or complaints. Seventy patients (13.4\%) fulfilled the inclusion criteria for this study, of which 64 $(91.4 \%)$ agreed to participate in it.

The descriptive analysis of the sample's demographical parameters showed that, of the 64 included individuals, $46(71.9 \%)$ were males and $18(28.1 \%)$ were females. Mean age in the sample was 57 years old (standard deviation $s d=9.2$ ), coinciding with the median, with minimum age being 34 and maximum 77 years. Mean age at the time of transplant was 47.3 years $(\mathrm{sd}=11.9)$ and median was 48 years, with minimum age 18 and maximum 69 years.

The sample's skin phototypes varied from I to $\mathrm{V}$ according to Fitzpatrick classification. The predominant phototype in the population was III (43.7\%), with $89 \%$ of individuals presenting skin phototypes up to III in the Fitzpatrick scale.

Thirty-five individuals (54.7\%) were from São Paulo city (capital), and the remainder $(45.3 \%)$ was from other cities in the countryside of São Paulo State.

Category variables of the demographical parameters, comprising personal habits and transplant issues with their respective percentage values are depicted on table 1.

The descriptive analysis of parameters regarding personal habits showed that 43 individuals $(67.2 \%)$ reported occupational sun exposure, with 
TABLE 1: Distribution of demographical parameters' category variables related to personal habits and transplant issues, with their respective absolute and percentage values. São Paulo, Brazil, 2004-2009

\begin{tabular}{|c|c|c|}
\hline Variables & $\mathrm{n}$ & $\%$ \\
\hline \multicolumn{3}{|l|}{ Gender } \\
\hline Male & 46 & (71.9) \\
\hline Female & 18 & $(28.1)$ \\
\hline \multicolumn{3}{|l|}{ Origin } \\
\hline São Paulo (capital) & 35 & $(54.7)$ \\
\hline São Paulo (countryside) & 29 & $(45.3)$ \\
\hline \multicolumn{3}{|l|}{ Phototype } \\
\hline I & 13 & $(20.3)$ \\
\hline II & 16 & $(25)$ \\
\hline III & 28 & $(43.7)$ \\
\hline IV & 6 & $(9.4)^{\prime}$ \\
\hline $\mathrm{V}$ & 1 & $(1.6)$ \\
\hline \multicolumn{3}{|l|}{ Occupational sun exposure } \\
\hline Yes & 43 & $(67.2)$ \\
\hline No & 21 & $(32.8)$ \\
\hline \multicolumn{3}{|l|}{ Time of sun exposure ${ }^{*}$} \\
\hline All day & 39 & $(90.7)$ \\
\hline Parts of the day & 4 & $(9.3)$ \\
\hline \multicolumn{3}{|l|}{ Recreational sun exposure } \\
\hline Yes & 41 & $(64.1)$ \\
\hline No & 23 & (35.9) \\
\hline \multicolumn{3}{|c|}{ Time of recreational sun exposure* } \\
\hline All day & 28 & $(68.3)$ \\
\hline Parts of the day & 13 & $(31.7)$ \\
\hline \multicolumn{3}{|c|}{ Type of recreational sun exposure* } \\
\hline Continuous & 10 & $(24.3)$ \\
\hline Sporadic & 31 & $(75.7)$ \\
\hline \multicolumn{3}{|l|}{ Photoprotection } \\
\hline Yes, regularly & 22 & $(34.4)$ \\
\hline Yes, irregularly & 28 & $(43.8)$ \\
\hline No & 12 & $(18.7)$ \\
\hline No, lack of exposure & 2 & $(3.1)$ \\
\hline \multicolumn{3}{|l|}{ Type of donor } \\
\hline Living & 41 & $(64.1)$ \\
\hline Deceased & 23 & $(35.9)$ \\
\hline \multicolumn{3}{|l|}{ Comorbidities } \\
\hline Yes & 59 & $(92.2)$ \\
\hline No & 5 & $(7.8)$ \\
\hline \multicolumn{3}{|l|}{ Pre-transplantation dialysis } \\
\hline Yes & 63 & $(98.5)$ \\
\hline No & 1 & $(1.5)$ \\
\hline \multicolumn{3}{|l|}{ Type of dialysis** } \\
\hline Hemodialysis & 45 & $(71.4)$ \\
\hline Peritoneal dialysis & 4 & $(6.4)$ \\
\hline Both & 14 & $(22.2)$ \\
\hline \multicolumn{3}{|l|}{ Previous transplantations } \\
\hline Yes & 2 & $(3.1)$ \\
\hline No & 62 & (96.9) \\
\hline
\end{tabular}

* Considering only individuals that reported sun exposure.

** Considering only individuals that were submitted to pre-transplantation dialysis.

duration of employment requiring such exposure ranging from two to 53 years, mean 19.6 years (sd = 13.2) and median of 15.0 years. The length of occupational sun exposure that predominated in the sample corresponded to the "all day" option, reported by 39 patients $(90.7 \%)$. Regarding the amount of time (in hours) of occupational sun exposure, 25 of 43 indivi- duals (58.2 \%) reported being exposed between eight and 12 hours.

Forty-one patients $(64.1 \%)$ reported recreational sun exposure. Among them, 31 (75.7\%) stated that the exposure did not occur daily, but sporadically (on weekends). The hours of recreational sun exposure that predominated in the sample corresponded also to the "all day" option, reported by 28 subjects (68.3\%). Considering the 41 individuals that reported recreational sun exposure, 30 (73.2\%) were exposed for more than two hours. The duration of recreational sun exposure (in years) ranged from one to 60 years, with mean of 24.8 years $(\mathrm{sd}=16.3)$ and median of 20 years.

Fifty patients $(78.1 \%)$ in the sample reported the use of sunscreen, but only $34.4 \%$ of them used it in a regular, daily manner (at least twice a day). Twelve individuals $(18.7 \%)$ reported no use at all of sunscreen, while two patients $(3.1 \%)$ reported no sun exposure. Of the 50 subjects using sunscreen, 46 $(92.0 \%)$ did so for the last 60 months.

Table 2 includes continuous variables related to personal habits parameters, with respective standard deviations, medians, minimum and maximum values and interquartile intervals, including occupational and recreational sun exposure.

In the descriptive analysis of skin cancer-related parameters, the predominant NMSC clinical type was squamous cell carcinoma (SCC), with 43 cases (67.2\%); followed by basal cell carcinoma (BCC), with 21 cases $(32.8 \%)$. The SCC/BCC ratio was 2:1. We considered, for this analysis, NMSC detected in patients during their consultation in this referral clinic.

Of the 64 individuals in the sample, $16(25 \%)$ already had a personal history of NMSC, while 48 $(75 \%)$ presented NMSC for the first time.

At the time of the interview, 26 individuals (40.6\%) had multiple NMSC, with lesion sites corresponding to photoexposed areas in 63 individuals (98.4\%).

The average latency time (in months) between transplantation and the onset of the first NMSC was 78.3 months ( $\mathrm{sd}=60.3)$, with a median of 64.5 months, minimum of seven months and maximum of 300 months. The analysis by clinical type showed that, the average latency times between transplantation and first SCC and BCC onsets were $72.9(\mathrm{sd}=56.8)$ and 89.4 months ( $\mathrm{sd}=66.9$ ), with median of 60.0 and 95.0 months, respectively.

Regarding family history of skin cancer, 57 subjects $(89.1 \%)$ reported negative past history and seven patients $(10.9 \%)$ reported positive history.

The presence of viral warts (human papillomavirus - HPV) after transplantation was observed in 34 subjects $(53.1 \%)$ in this study. The average latency time between transplantation and the onset of viral warts was 71.5 months $(\mathrm{sd}=56.1)$, with a minimum 
TABLE 2: Mean values and corresponding standard deviations (sd), medians, minimum and maximum values (minimum-maximum) and interquartile intervals (IIQ or IQ) of continuous variables related to personal habits. São Paulo, Brazil, 2004-2009

\begin{tabular}{|c|c|c|c|c|}
\hline Variable & Mean (sd) & Median & Minimum-maximum & IIQ \\
\hline Duration of occupational sun exposure (in years)* & $19.6(13.2)$ & 15.0 & $2-53$ & $10.0-30.0$ \\
\hline Number of hours of occupational sun exposure (daily)* & $7.6(3.0)$ & 8.0 & $2-12$ & $5.0-10.0$ \\
\hline Duration of recreational sun exposure (in years)* & $24.8(16.3)$ & 20.0 & $1-60$ & $10.0-36.5$ \\
\hline Number of hours of recreational sun exposure (daily)* & $5.5(3.2)$ & 5.0 & $1-12$ & $2.0-8.0$ \\
\hline Length of photoprotection (in months) ${ }^{* *}$ & $35.8(37.5)$ & 24 & $0-204$ & $7.5-51.0$ \\
\hline
\end{tabular}

* Considering only the individuals that reported sun exposure.

** Considering only the individuals that reported photoprotection.

time of six months and maximum period of 240 months.

The descriptive analysis of transplant-related parameters showed that the average time of transplantation in this sample was 115.5 months $(\mathrm{sd}=72.6)$, with a minimum of 18 months and maximum time of 385 months.

Living donors were the predominant donor type in the sample, with 41 cases (64.1\%).

The cause of renal function loss was known for 53 patients $(82.8 \%)$ in the sample and unidentified for the other 11 subjects (17.2\%). The main cause of chronic renal failure was systemic hypertension, in 30 cases (46.9\%); followed by nephritis, in 10 cases (15.7\%); and polycystic renal disease, in four cases (6.3\%). Diabetes mellitus accounted for $4.7 \%$ of the cases.

Therapeutic schemes used for post-transplant immunosuppression were varied. All patients in this study underwent treatments with two or three drugs. The triple scheme was used in 47 cases $(73.4 \%)$, and the double scheme in 17 individuals (26.6\%). Drugs used for post-transplant immunosuppression in the 64 subjects included in this study were: prednisone, tacrolimus, cyclosporine, azathioprine, mycophenolate mofetil, mycophenolate sodium, sirolimus, everolimus and RAD (drug in research protocol). Prednisone was the most used drug (61 subjects, $95.3 \%$ ).

Fifty-nine subjects $(92.2 \%)$ presented comorbidities.

Of the 64 subjects included in this study, 63 (98.4\%) underwent pre-transplant dialysis. Among them, the predominant dialysis modality was hemodialysis, with $71.4 \%$; followed by the association of hemodialysis/peritoneal dialysis in $22.2 \%$. Peritoneal dialysis alone corresponded to $6.4 \%$ of the sample population. The mean duration of dialysis before transplantation was 39.1 months ( $\mathrm{sd}=31.3)$, with minimum time of eight months and maximum of 144 months.

Two patients $(3.1 \%)$ reported previous transplant in this study.

\section{DISCUSSION}

Skin cancers are the most common malignancy among RTRs, representing almost $50 \%$ of the tumors in this population., ${ }^{3,4}$ The reason for the dramatic increase in their incidence among these patients is due to a reduction of immunosurveillance against cancer caused by immunosuppressive antirejection regimens, coupled with ultraviolet radiation (UVR) exposure. ${ }^{5}$

NMSC are associated with significant morbidity and mortality in organ transplant recipients (OTR) ${ }^{6,7}$ They directly affect the viability of the transplant and the recipient, as well as the patient's quality of life, due to the need for alterations on immunosuppressive regimens and the associated risk of graft loss. Moreover, they present a more aggressive clinical course in this group than in the immunocompetent population. ${ }^{6,8}$ In the present study, the overall incidence of NMSC in 524 RTRs treated at the referral center during the pre-determined period was 13.3\%, which was higher than those reported in other relevant studies. ${ }^{4,5}$ The prevailing tropical climate in the state of São Paulo and its geographic latitude likely contribute in part to explaining this finding, as well as the referral bias of RTRs with more evident cutaneous lesions on clinical examinations performed by general practitioners or nephrologists.

This work was not aimed at analyzing the prevalence of NMSC in the universe of HSP and HRH renal transplant recipients, but only in the group of patients who were referred from these institutions by their general practitioners or nephrologists with dermatological complaints or lesions to the solid organ transplant division of the department of dermatology at UNIFESP-EPM. Thus, we cannot extrapolate the frequencies found in other studies.

Regarding gender, our data were in agreement with the literature, which even points the male gender as a risk factor for the development of NMSC in RTRs. ${ }^{4.8}$ The higher incidence of renal transplants in males, greater UVR exposure and lower adherence to photoprotection guidelines may justify this finding. ${ }^{9}$

Analyses of patients' mean age at the moment of tumor diagnosis were not found in the literature; studies reported only age at transplant, which would be directly proportional to the risk of developing skin cancer in RTRs. ${ }^{48}$ The mean age at transplant found in this study, around the fourth decade of life, is in consonance with data from national and international reports. ${ }^{46,69,10}$ 
The risk of developing NMSC is higher in people with fair skin, light hair and eyes, which have difficulties in tanning and a tendency to sunburn. These characteristics coincide with the profile found in this sample, in which $89 \%$ of the subjects had skin phototypes up to III in Fitzpatrick scale, with $45.3 \%$ presenting skin phototypes II or I. ${ }^{11}$ Studies conducted in the immunocompetent population in this same region (São Paulo state) found Fitzpatrick skin phototypes II or lower as a susceptibility factor for the development of NMSC and also showed skin cancer occurrence ratio among whites and nonwhites of $4: 1 .^{12-15}$ The incidence of NMSC in RTRs with higher skin phototypes (III / IV), as observed in this study, is found in the literature and can be supported by the interference of antirejection immunosuppression regimens outweighing the individual genetic predisposition. ${ }^{7,13}$

The UVR present in sunlight is clearly the most important physical environmental carcinogen for the development of skin cancer. ${ }^{16}$ The cumulative UVR exposure in pre-and post-transplantation years is directly related to NMSC pathogenesis. UVR alone has the ability to initiate, promote and induce the progression of skin cancers. ${ }^{5}$ Considering the information above, this study's findings, regarding personal habits (occupational and recreational sun exposure and photoprotection), also contributed to the high overall incidence of NMSC detected in this sample.

Regarding clinical type, SCC predominated in this population, similarly to the findings of Zavos et al., Ramsay et al. and Falsarella et al. and in contrast to the findings of Fuente et al. ${ }^{4,6,7,9}$

The presence of multiple tumors of the same strain or different strains at the moment of diagnosis, observed in this study, had already been reported in other relevant papers, and the predilection for photoexposed areas was a consensus in the medical literature. ${ }^{4.8}$

The average latency period between transplantation and the onset of the first NMSC is variable in the literature. ${ }^{6,10}$ Our findings, regarding the average latency time according to NMSC clinical type, were contrary to those found in the literature, which point to a longer quiescence period for SCC. ${ }^{6,9}$ The mean latency time of 72.9 months for SCC versus 89.4 months for BCC could be explained by the lower frequency of the latter.

Reports on family history of NMSC in RTRs were not found in the literature. However, we emphasize the low rates of family history $(10.9 \%)$ among these patients, demonstrating that immunosuppression is a determining factor for NMSC development.

Studies have shown relevant interactions between HPV and UVR, cytokines and host cell proteins, including p53 and pro-apoptotic protein Bak, from Bcl-2 family, contributing to malignant transformation in cutaneous keratinocytes and the appearance of NMSC in immunocompetent and immunosuppressed populations., ${ }^{5,17}$ HPV presence was observed in more than half of the individuals in this study, which may be acting as a tumor promoter, thus deserving further investigation in this population.

Living donors were the predominant donor type in this sample, in contrast with the findings of Ramsay et al. and Kasiske et al, who found a predominance of deceased donors: $82.4 \%$ and $76 \%$ respectively. ${ }^{10,18}$ Transplantations performed with live donor organs do not usually demand intense immunosuppression as those that use organs from deceased donors; however, the organ origin did not seem to have interfered in this analysis.

The variability in treatment regimens found in the present study was also reported in the literature. The adopted schemes also consisted of two or three medications, always a systemic steroid (prednisone) associated with one or two drugs. ${ }^{6,9,10,19}$ Comparative studies between double and triple antirejection regimens demonstrated that the level of immunosuppression - rather than the use of a particular agent/drug gives the proportional risk of NMSC development. ${ }^{6}$ Thus, the triple scheme, predominant in our sample, is associated with an increased risk for NMSC compared to the double regimen, which may explain the higher overall incidence of NMSC found in this referral center.

The presence of comorbidities $(92.2 \%$ in this study) has not been evaluated in the researched literature. In general, most RTRs have comorbidities due to the use of immunosuppressive drugs or secondary to the conditions that caused renal function loss, such as hypercholesterolemia, hypertension, diabetes mellitus and nephritis.

The mean duration of pre-transplant dialysis in the literature ranged from 1.4 years (data by Ramsay et al.) to three years or more (demonstrated by Kasiske et al.), with the latter being more in line with the findings in this study., ${ }^{9,10}$ The type of dialysis was not reported by the authors. In general, RTRs receiving deceased donor organs are submitted to dialysis before transplantation, with all the accompanying complications arising from this procedure, such as serological conversion to viral infections. Therefore, individuals undergoing dialysis have higher incidence of comorbidities.

The cause of renal function loss is controversial in the literature, but primary kidney diseases (glomerular, interstitial, polycystic, vascular), diabetes mellitus and hypertension are among the main causes in all studies. ${ }^{6,9,18}$ 


\section{CONCLUSION}

This study allowed us to describe the epidemiological profile of RTRs with NMSC seen at the solid organ transplant division of the department of dermatology at UNIFESP-EPM, during the period of August $1^{\text {st }} 2004$ to August 31 ${ }^{\text {st }} 2009$; with findings sometimes consistent, sometimes conflicting with national and international literature. However, the data presented in this study permitted the identification of RTRs with higher risk of developing NMSC.

\section{REFERENCES}

1. Mutti AEC, Menezes A, Magalhães TN, Lopes ML. Distribuição da procedência de pacientes operados de câncer de pele não-melanoma no Hospital Aristides Maltez e sua relação com mapeamento populacional no estado da Bahia. Rev Baiana Saúde Pública. 2004; 28:227-41.

2. Ridky TW. Nonmelanoma skin cancer. J Am Acad Dermatol. 2007;57:484-501.

3. Moloney FJ, Comber H, O'Lorcain P, O'Kelly P, Conlon PJ, Murphy GM. A populationbased study of skin cancer incidence and prevalence in renal transplant recipients. $\mathrm{Br}$ J Dermatol. 2006; 154:498-504.

4. Falsarella PM, Alves-Filho G, Mazzali M. Skin malignancies in renal transplant recipients: a Brasilian center registry. Transplant Proc. 2008;40:767-8.

5. Ho WL, Murphy GM. Update on the pathogenesis of post-transplant skin cancer in renal transplant recipients. Br J Dermatol. 2008;158:217-24.

6. Zavos G, Karidis NP, Tsourouflis G, Bokos J, Diles K, Sotirchos G, et al. Nonmelanoma skin câncer after renal transplantation: a single-center experience in 1736 transplantations. Int J Dermatol. 2011;50:1496-500.

7. Ramsay HM, Reece SM, Fryer AA, Smith AG, Harden PN.. Seven-year prospective study of nonmelanoma skin cancer incidence in U.K. renal transplant recipients. Transplantation. 2007;84:437-9.

8. Bouwes Bavinck JN, Hardie DR, Green A, Cutmore S, MacNaught A, O'Sullivan B, et al. The risk of skin cancer in renal transplant recipients in Queensland, Austrália: a follow-up study. Transplantation. 1996;61:715-21.

9. Fuente MJ, Sabat M, Roca J, Lauzurica R, Fernández-Figueras MT, Ferrándiz C. A prospective study of the incidence of skin cancer and its risk factors in a Spanish Mediterranean population of kidney transplant recipients. $\mathrm{Br} J$ Dermatol. 2003;149:1221-6.

10. Ramsay HM, Fryer AA, Hawley CM, Smith AG, Harden PN. Non-melanoma skin cancer risk in the Queensland renal transplant population. 2002; 147: 950-56.

11. Nasser N. Epidemiologia dos carcinomas basocelulares em Blumenau, SC, Brasil, de 1980-1999. An Bras Dermatol. 2005;80:363-8.

12. Ferreira FR, Nascimento LFC, Rotta 0 . Fatores de risco para câncer da pele não melanoma em Taubaté-SP: um estudo caso-controle. Rev Assoc Med Bras. 2011;57:431-7.

13. Bariani RL, Nahas FX, Barbosa MV, Farah AB, Ferreira LM. Basal cell carcinoma: an updated epidemiological and therapeutically profile of an urban population. Acta Cir Bras. 2006;21:66-73.

\section{ACKNOWLEDGEMENTS}

We thank University of Taubaté (Unitau) that granted a doctoral scholarship to the author, whose thesis originated this article.
14. Maia M, Proença NG, de Moraes JC. Risk factors for basal cell carcinoma: a case control study. Rev Saude Publica. 1995;29:27-37.

15. Ferreira FR, Nascimento LFCN. Skin cancer in Taubaté (SP) - Brazil, from 2001 to 2005: a prevalence study . An Bras Dermatol. 2008;83:317-22.

16. Rocha FP, Menezes AMB, Almeida Junior HL, Tomasi E. Risk markers and risk factors for actinic keratosis and basal cell carcinoma: a case-control study. An Bras Dermatol. 2004; 79: 441-54.

17. Harwood CA, Proby CM. Human papillomaviruses and non-melanoma skin cancer. Curr Opin Infect Dis. 2002;15:101-14.

18. Kasiske BL, Snyder JJ, Gilbertson DT, Wang C. Cancer after Kidney Transplantation in the United States. Am J Transplant. 2004;4:905-13.

19. Tessari G, Naldi L, Boschiero L, Nacchia F, Fior F, Forni A, et al. Incidence and Clinical Predictors of a subsequent Nonmelanoma Skin Cancer in Solid Organ Transplant Recipients with a First Nonmelanoma Skin Cancer. Arch Dermatol. 2010;146:294-9.

How to cite this article: Ferreira FR, Ogawa MM, Nascimento LFC, Tomimori J. Epidemiological profile of nonmelanoma skin cancer in renal transplant recipients: experience of a referral center. An Bras Dermatol. 2014;89(5):745-50. 